\title{
PERANCANGAN PENCATATAN DAN PELAPORAN TERPADU PUSKESMAS BERBASIS E-REPORT UNTUK MENINGKATKAN KESEHATAN MASYARAKAT
}

\author{
Nasrul Nazir ${ }^{1}$, Gusnita Darmawati \\ Prodi Sistem Informasi, AMIK Bukittinggi \\ Email : nasrulahnazir2814@gmail.com
}

\begin{abstract}
ABSTRAK : Mutu pelayanan kesehatan yang diberikan kepada masyarakat dapatditingkatkan dengan baik apabila didukung oleh sistem pelaporan yang baik yaitu informasi lengkap dan data tersebut harus diterima tepat waktu.Sistem pencatatan dan pelaporan terpadu puskesmas (SP2TP) ke dinas kesehatan kota Bukittinggi masih dilakukan dengan menyerahkan file berupa hardcopy kepada dinas kesehatan kota sehingga dinas kesehatan kota harus merekapitulasi lagi pelaporan yang akan memerlukan waktu lama dan kemungkinan akan terjadi duplicate data.Tujuan dari penelitian ini adalah terciptanya e-report yang menggambarkan informasi yang akurat, representatif dan reliable yang dapat dijadikan pedoman dalam penyusunan perencanaan kesehatan masyarakat. Dalam penelitian ini menggunakan metode waterfall yang mana membantu dalam perancangan sistem mulai dari desain, pengujian sampai implementasi sedangkan untuk memodelkan rancangan sistem menggunakan UML (Unified ModelingLanguage). Hasil dari penelitian ini adalah sistem informasi pelaporan data SP2TP lewatmedia website atau secara online yang dapat digunakan oleh pegawai setiap puskesmas dalam lingkungan dinas kesehatan kota bukittinggi.
\end{abstract}

Kata Kunci: SP2TP, puskesmas, e-report

\section{PENDAHULUAN}

Setiap puskesmas diwajibkan untuk mencatat, menganalisa dan membuat laporan tentang pelaksanaan program yang sedang dilaksanakan puskesmas yang dikenal dengan istilah sistem pencatatan dan pelaporan terpadu Puskesmas (SP2TP). SP2TP dilakukan dengan cara manual dan dingantar pelaporan SP2TP dengan menyerahkan file berupa hardcopy kepada dinas kesehatan kota maka ini memakan waktu,tenaga dan biaya mengingat lokasi dinas kesehatan ada dipusat kota sedangkan puskesmas terpencar di beberapa kelurahan. Adapun tujuan dari penelitian ini adalah:

1. Merancang pencatatan dan pelaporan terpadu puskesmas berbasis ereportsehingga memudahkan dinas kesehatan kota dalam menampung dan memonitor serta menganalisa pelaporan puskesmas

2. Mengintegrasikan SP2TP sehingga mendukung manajemen informasi untuk kualitas dan kecepatan proses kerja pada dinas kesehatan kota

3. Untuk menunjang peningkatan pelayanan kesehatan masyarakat dengan cara pengambilan keputusan

yang lebih cepat berdasarkan informasi yang interaktif di website

4. E-reportdigunakanuntuk

memfasilitasi setiap pelaporan SP2TP dari puskesmas secara online

5. Mengoptimalkan penggunaan sistem komputer didunia kerja terutama

Didinas pemerintahan baik puskesmas maupun dinas kesehatan kota.

\section{Sistem Pencatatan Dan Pelaporan Terpadu Puskesmas (SP2TP)}

Puskesmas merupakan fasilitas pelayanan publik yang menyelenggarakan kesehatan masyarakat dan kesehatan perseorangan tingkat pertama, dengan lebih mengutamakan upaya promotif dan preventif, untuk mencapai derajat kesehatan 
masyarakat yang setinggi-tingginya. Puskesmas merupakan ujung tombak pelayanan kesehatan masyarakat di masyarakat. Untuk mengoptimalkan fungsi puskesmas tersebut maka puskesmas harus didukung oleh ketersedian data dan informasi secara akurat terkini berkelanjutan dan dapat dipertanggungjawabakan. Dukungan data dan informasi tersebut digunakan sebagai masukan system perencanaan dan evaluasi program sesuai dengan analisis kebutuhan dalam manajemen penyelenggaraan puskesmas.

\section{METODE PENELITIAN}

Penelitian ini menggunakan metode waterfall, hal ini menggambarkan pendekatan yang sistematis dan juga berurutan padapengembangan perangkat lunak, dimulai dengan spesifikasi kebutuhan pengguna lalu berlanjut melalui tahapan perencanaan, permodelan, konstruksi serta penyerahan sistem ke para pengguna (deployment), yang diakhiri dengan dukungan perangkat lunak lengkap yang dihasilkan (Pressman, 2012).

\section{Requirement Analisis}

Tahap ini pengembangan system memerlukan komunikasi yang bertujuan untuk memahami perangkat lunak yang diharapkan oleh pengguna dan batasan perangkat lunak tersebut. Informasi ini biasanya dapat diperoleh melalui wawancara, diskusi atau survey langsung. Informasi dianalisis untuk mendapatkan data yang dibutuhkan oleh pengguna.

\section{System Design}

Spesifikasi kebutuhan dari tahap sebelumnya akan dipelajari dalam fase ini dan desain sistem disiapkan. Desain sistem membantu dalammenentukanperangkatkeras dan sistem persyaratan dan juga membantu dalam mendefensikan arsitektur sistem secara keseluruhan.

\section{System Design}

Spesifikasi kebutuhan dari tahap sebelumnya akan dipelajari dalam fase ini dan desain sistem disiapkan. Desain sistem membantu dalam menentukan perangkat keras dan sistem persyaratan dan juga membantu dalam mendefensikan arsitektur sistem secara keseluruhan.

\section{Implementation}

Pada tahap ini, sistem pertama kali dikembangkan program kecil yang disebut unit, yang terintegrasi dalam tahap selanjutnya. Setiap unit dikembangkan dan diuji untuk fungsi yang disebut sebagai unit testing.

\section{Integration \& Testing}

Seluruh unit yang dikembangkandalam tahap implementasi diintegrasikan ke dalam sistem setelah pengujian yang dilakukanmasing-masing unit. Setelah integrasi seluruh sistem diuji untuk mengecek setiap kegagalan maupun kesalahan.

\section{Operation \& Maintenance}

Tahap akhir dalam model waterfall. Perangkat lunak yang Sudah jadi, dijalankan serta dilakukan pemeliharaan. Pemeliharaan termasuk dalam memperbaiki kesalahan yang tidak Ditemukan pada langkah sebelumnya. Perbaikan implementasi unit sistem dan peningkatan jasa sistem sebagai kebutuhan baru.

\section{System Design}

Spesifikasi kebutuhan dari tahap sebelumnya akan dipelajari dalam fase ini dan desain sistem disiapkan. Desain sistem membantu dalammenentukanperangkatkeras dan sistem persyaratan dan juga membantu dalam mendefensikan arsitektur sistem secara keseluruhan.

\section{System Design}


Spesifikasi kebutuhan dari tahap sebelumnya akan dipelajari dalam fase ini dan desain sistem disiapkan. Desain sistem membantu dalam menentukan perangkat keras dan sistem persyaratan dan juga membantu dalam mendefensikan arsitektur sistem secara keseluruhan.

\section{Implementation}

Pada tahap ini, sistem pertama kali dikembangkan program kecil yang disebut unit, yang terintegrasi dalam tahap selanjutnya. Setiap unit dikembangkan dan diuji untuk fungsi yang disebut sebagai unit testing.

\section{Integration \& Testing}

Seluruh unit dikembangkandalam tahap implementasi diintegrasikan ke dalam sistem setelah pengujian yang dilakukanmasing-masing unit. Setelah integrasi seluruh sistem diuji untuk mengecek setiap kegagalan maupun kesalahan.

\section{Operation \& Maintenance}

Tahap akhir dalam model waterfall. Perangkat lunak yang Sudah jadi, dijalankan serta dilakukan pemeliharaan. Pemeliharaan termasuk dalam memperbaiki kesalahan yang tidak Ditemukan pada langkah sebelumnya. Perbaikan implementasi unit sistem dan peningkatan jasa sistem sebagai kebutuhan baru.

\section{ANALISA DAN PEMBAHASAN}

\section{Analisa Sistem Sedang Berjalan}

Proses pelaporan SP2TP untuk masingmasing puskesmas dikirim ke dinas kesehatan Kota setiap bulan.

Dinas Kesehatan Kota mengolah kembali laporan puskesmas dan mengirimkan umpan balik ke dinas kesehatan provinsi dan departemen kesehatan pusat. Umpan balik terhadap laporan puskesmas harus dikirim kembali secara rutin ke puskesmas untuk dapat dijadikan evaluasi keberhasilan program puskesmas dan peningkatan pelayanan puskesmas.

Sistem yang sedang berjalan saat ini pencatatan dan pelaporan puskesmas kota masih dilakukan secara manual, yaitu dengan mengisi blanko yang telah dicetak dan dibagikan kepada semua pegawai puskesmas yang menjadi penanggung jawab pelaksanaan program kegiatan rutin puskesmas.

Hasil dari pelaksanaan program dilaporkan dengan memasukkan data ke dalam kertas blanko isian yang telah dibagikan sebelumnya. seluruh laporan yang telah diisi dikumpulka ke penanggung jawab program SP2TP untuk disatukan dan dilaporkan ke dinas kesehatan. Proses yang sedang berjalan ini memiliki beberapa kelemahan dan kekurangan antar lain

1. Pengiriman laporan SP2TP sering mengalami keterlambatan oleh petugas puskesmas.

2. Sering terjadi laporan yang dikirim masih kurang lengkap.

3. Dinas Kesehatan Kota perlu merekapitulasi ulang satu persatu data yang dikirim oleh masing-masing puskesmas.

4. Kurang koordinasi antara penelola data di Dinas Kesehatan Kota dengan petugas puskesmas dalam pengiriman laporan. 


\section{A. Desain Sistem Baru}

\section{Use Case Diagram}

Use case diagram merupakangambaran global dari system yang dirancang. Pada use case ini digambarkan kegitan yang dilakukan oleh setiap masing-masing aktor yang terlibat dalam sistem ini. Aktor yang terlibat dalam sistem ini adalah :

a. Admin

b. Kepala Puskesmas

c. Petugas Puskesmas

d. Kepala Dinas

Tugas dan fungsi dari masing masing aktor adalah :

Berdasarkan deskripsi kegiatan dari aktor di atas maka dapat digambarkan use case dari sistem seperti di bawah ini :

\section{Activity Diagram}

Activity diagram merupakan gambaran alur kegiatan yang dilakukan oleh masing-masing aktor. dimulai dari admin yang mengelola data master dan data. Kemudian petugas pelaksana mengumpulkan data kegiatan SP2TP dan mengimputkan data tersebut ke sistem. kemudian admin mencetak data SP2TP. Berdasarkan data yang dicetak kepla puskesmas melakukan kontrol terhadap data

yang ada. dan melakukan verifikasi laporan SP2TP. Data yang sudah dinputkan dikontrol oleh dinas kesehatan kota.

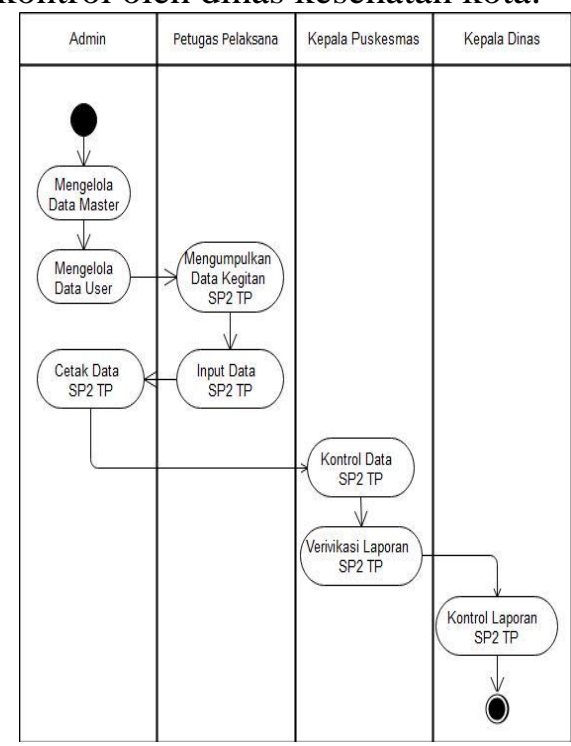

Gambar 1. Aktivity Diagram Pelaksanaan SP2TP

\section{Desain Database}

Database adalah kumpulan dari table-tabel. Sedangkan table merupakan kumpulan record-record yang mempunyai type sama dan saling terkait dan saling mendukung satu sama lainnya. Fungsi table tersebut adalah sebagai penyimpanan data, agar dapat diakses dan dicetak ke dalam sebuah laporan. Bentuk rancangan tabel tersebut dapat dilihat dari format berikut:

\section{a. Tabel Pengguna}

Tabel ini mempunyai kegunaan untuk menyimpan data pengguna yang terlibat dalam penggunaan sistem ini. Pada table ini juga digunakan untuk mengontrol hak akses dari pengguna. 
Database Laporan Data User

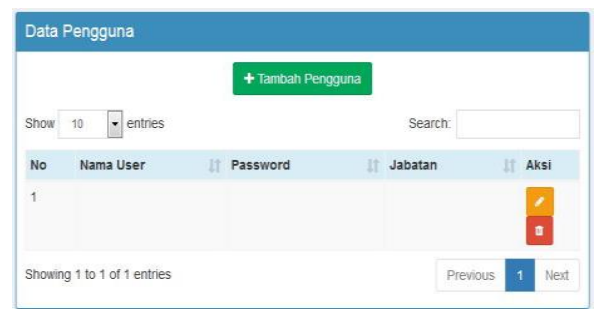

Gambar 2. Laporan Data Pengguna

a. Laporan Data Kecamatan

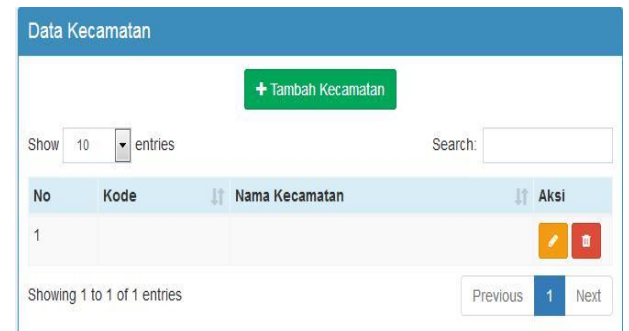

Gambar 3. Laporan Data Kecamatan

b. Laporan Data Puskesmas

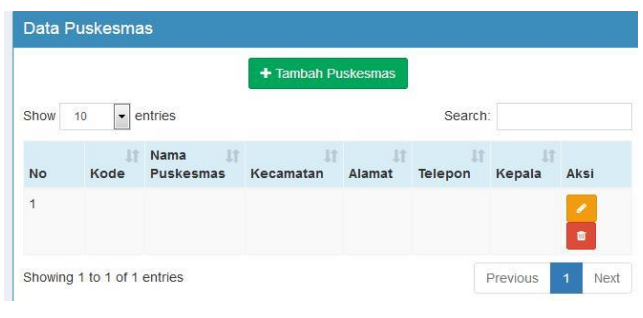

Gambar 4. Laporan Data Puskesmas

c. Laporan Data Pegawai

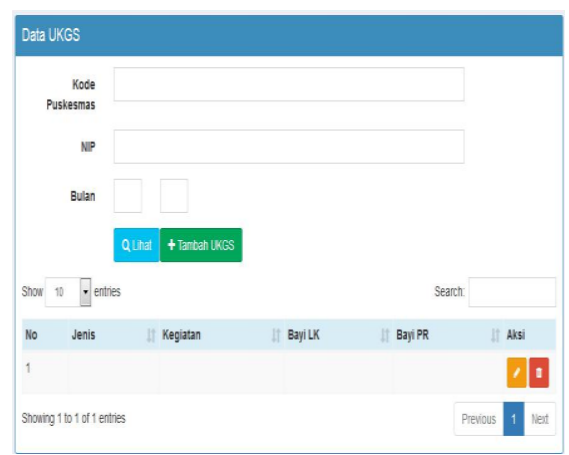

Gambar 5. Laporan Data Pegawai d. Laporan Ibu Hamil

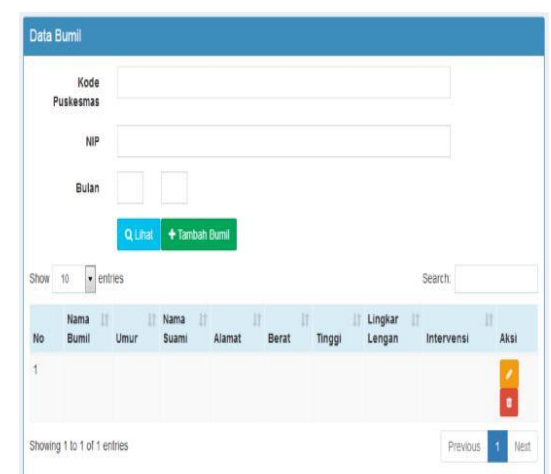

Gambar 6. Laporan Data Ibu Hamil

e. .Laporan Data Imunisasi

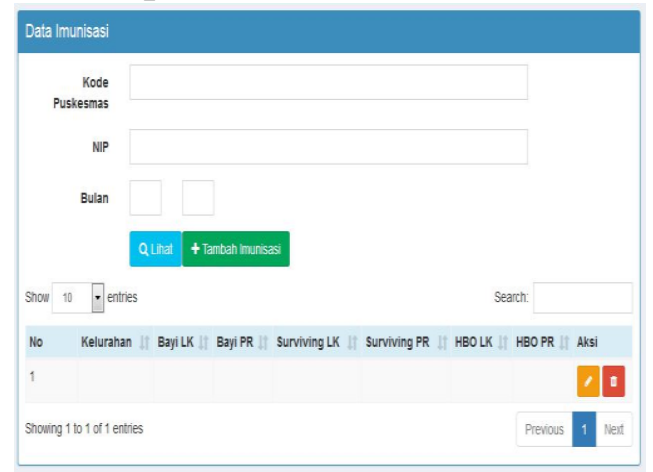

Gambar 7. Laporan Data Imunisasi

\section{f. Laporan Data UKGS}

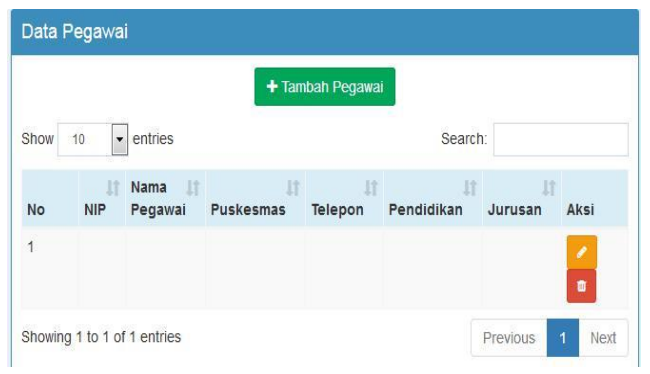

Gambar 8. Laporan Data UGKS 


\section{g. Laporan Data KB}

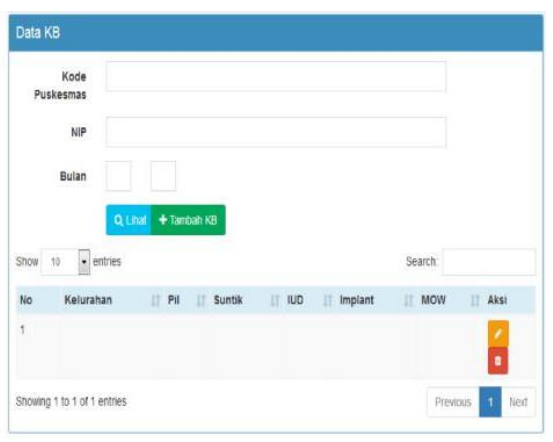

Gambar 9. Laporan Data Peserta KB

\section{h. Laporan Data Penyakit}

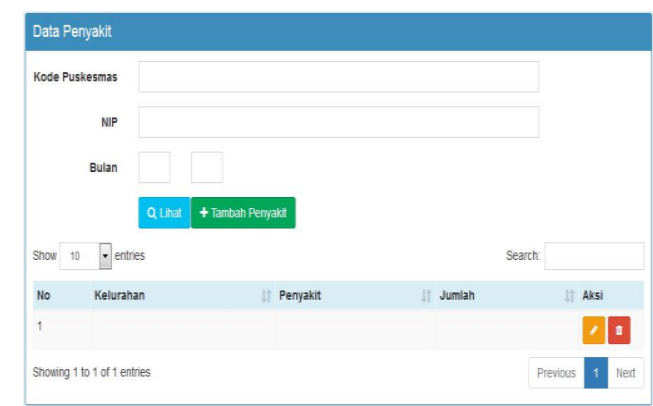

Gambar 10. Laporan Data Penyakit

\section{PENUTUP}

\section{A. Kesimpulan}

Berdasarkan penelitian yang telah dilakukan pada Dinas Kesehatan Kota Bukittinggi dapat dinarik kesimpulan sebagai berikut:

1. Dengan adanya aplikasi sistem informasi pelaporan data SP2TP mampu memudahkan Puskesmas untuk melaporkan SP2TP ke dinas kesehatan kota.

2. Dengan adanya aplikasi sistem informasi pelaporan data SP2TP ini dinas kesehatan kota dapat dengan mudah mengontrol dan

merekap data SP2TP yang dilaporkan oleh semua Puskesmas dengan cepat dan tepat waktu

3. Dengan mudahnya pengontrolan dan merekap pelaporan maka dinas kesehatan dapat dengan cepat mengambil keputusan yang tepat dan cepat untuk meningkatkan tingkat kesehatan masyarakat kota.

\section{B. Saran}

Hasil kesimpulan di atas penelitian yang dilakukan, maka dapat kedepankan beberapa saran yang diharapkan dapat menjadi bahan pertimbangan lebih lanjut dalam upaya pengembangan sistem di masa yang akan datang. Adapun saran yang disampaikan adalah:

1. Setelah adanya perancangan sistem informasi pelaporan SP2TP yang terkomputerisasi di dinas kesehatan diharapkan mampu meningkatkan kualitas pelayanan kesehatan masyarakat kota

2. Untuk lancarnya pelaksanaan pelaporan dan agar sistem berjalan dengan baik dinas kesehatan disarankan untuk mengadakan pelatihan dan perekrutan pegawai untuk menjaga sistem gar dapat berjalan dengan baik.

\section{DAFTAR PUSTAKA}

Jogiyanto.2009. Sistem Teknologi Informasi. Andi:Yogyakarta.

Kadir, Abdul. 2008. Belajar Data Base Menggunakan My SQL. Yogyakarta: CV Andi Offset

Kristanto, Andri. 2007. Perancangan Sistem Informasi dan Aplikasinya. Gava Media: Yogyakarta.

L. Dwiartara, Menyelam dan Menaklukan Samudra PHP "edisi 2." 2013.

Madcoms.2009. Menguasai XHTML, CSS, PHP, My SQL Melalui Dream weaver. Andi: Yogyakarta. 
P.Sulistyorini,"Pemodelan Visual dengan Menggunakan UML dan Rational Rose," J. Teknol. Informasi Din., vol. Vol XIV, N, pp.23-29, 2009.

Sutabri,Tata.2012.Analisa Sistem Informasi. Yogyakarta: CV Andi Offset

Widodo,Prabowo, Herlawati. 2011 Menggunakan UML. Informatika: Bandung. 